\title{
The role of rolling forecasting in budgetary control systems: reactive and proactive types of planning
}

\author{
Tiina Henttu-Aho ${ }^{1}$ \\ Published online: 28 December 2018 \\ (c) The Author(s) 2018
}

\begin{abstract}
The paper examines how rolling forecasting is used in planning and linked to other practices in a management control system. The paper combines a function-based view of budgeting with a more disaggregation-based conceptualisation, considering individual control systems. A multiple-case-study approach was adopted to investigate differences in the design and use of control systems across three industrial firms that had recently sought to improve their planning. The findings reveal two approaches to forecasting. In proactive-type planning, rolling forecasting was employed to promote information oriented toward more realistic forecasts and ideas emerging from interactive discussion were often put into action before quantified monetary deviations between plans and targets emerged. In reactive planning, rolling forecasting supported the supremacy of annual budgeting, and a more stable, joint process for both enabled analysing variances formally in a diagnostically oriented manner and revising plans accordingly. Synergies between budgetary practices were also found-for instance, in the process of setting targets, wherein the forecasts informed managers of the outcome level that was likely to be achievable and hence served as a realistic basis for setting more demanding targets.
\end{abstract}

Keywords Forecasting $\cdot$ Functions of budgeting $\cdot$ Planning $\cdot$ Budgetary control system · Diagnostic use $\cdot$ Interactive use

JEL Classification M10 - M40

Tiina Henttu-Aho

tiina.henttu-aho@oulu.fi

1 Department of Economics, Accounting and Finance, Oulu Business School, University of Oulu, P.O. Box 8000, 90014 Oulu, Finland 


\section{Introduction}

Recent budgeting research has become more extensively informed about the various functions ${ }^{1}$ (e.g. planning, control and evaluation) that budgeting serves (Hansen and Van der Stede 2004; Sivabalan et al. 2009; Henttu-Aho and Järvinen 2013; Becker et al. 2016). Accordingly, the focus of research is shifting from assessing the effects of budgeting in an aggregate manner toward considering the importance of the individual functions of budgeting and the associated implications for control systems' design in various organisational settings (Sponem and Lambert 2016). In particular, the planning function of budgeting has been found to grow more prominent in volatile business environments or a shaky economy, with organisations often addressing the uncertainty by turning to more frequent forecasts or to scenario work (Becker et al. 2016; Goretzki and Messner 2016; Palermo 2018). Notwithstanding this utility, it appears that the intentions behind more predictive accounting practices can sometimes be controversial from the standpoint of budgetary functions, leading to confusion and contradictions if there is failure to distinguish between the core purposes of planning and evaluation.

The role of rolling forecasting in planning involves its own intriguing contradictions: while practice-oriented literature often suggests it as an alternative to annual budgeting (Cosper 2012; Zeller and Metzger 2013), it seems to get incorporated into management control systems in various ways. In the accounting literature, some scholars find strong overlap between the role of forecasting in planning and the evaluation function of annual budgeting, hence referring to 're-budgeting' (Becker et al. 2016) or 'rolling budgeting'. ${ }^{2}$ Researchers applying that framing tend to see more frequent (i.e., rolling) setting of budget goals as problematic, especially in a stable business climate (Haka and Krishnan 2005; Hansen and Van der Stede 2004; Hansen 2011). Others view rolling forecasting more as a complementary tool supporting the planning and control functions of annual budgeting and as having its place in a hybrid system composed of various accounting instruments (Ekholm and Wallin 2000; Sivabalan et al. 2009; Henttu-Aho and Järvinen 2013). Finally, some studies indicate that in an environment without annual budgeting the process of rolling forecasting becomes a key part of planning. This position is visible in the organisational mix of controls called Beyond Budgeting, in which target-setting is separated from the flows of planning (Østergren and Stensaker 2011; Bourmistrov and Kaarbøe 2013). These contradictory conceptions imply that rolling forecasting might well play many of several roles in connection with the annual budgeting process or in connection to another mix of controls, and highlight

\footnotetext{
1 Some recent studies have operated with the concept 'functions of budgeting' (Hansen 2011; Bourmistrov and Kaarbøe 2013; Henttu-Aho and Järvinen 2013; Becker et al. 2016), while earlier studies sometimes applied concepts referred to as 'reasons-to-budget' and 'purposes of budgeting' (Ekholm and Wallin 2000; Covaleski et al. 2003; Hansen and Van der Stede 2004; Sivabalan et al. 2009). In this paper, we use the term 'functions of budgeting' because, at least in its original use, it seems to imply a wider perspective on functions, encompassing elements beyond merely the evaluation function of budgeting. In this work, the concept of functions of budgeting is used also in connection with other management control systems than annual budgeting.

2 In the accounting literature, using a 'rolling budget' is sometimes regarded as an alternative to traditional budgeting; in this approach, managers use 'continuous forecasting' to update the budget (Haka and Krishnan 2005; Hansen and Van der Stede 2004; Hansen 2011).
} 
a need for research to delve more deeply into the interrelations among practices serving various functions typical of budgeting (Hansen and Van der Stede 2004).

The variety of roles that rolling forecasting plays in management control systems may be explained in part by the degree of goal-orientation they embody or the existence of a motivational component in planning (see Malmi and Brown 2008; Goretzki and Messner 2016). Even though planning sometimes is seen as only supporting ex ante decision-making and hence as separate from the management control per se, in budgetary control it plays a vital role in creating goal congruence in the organisation and thus is always linked in some way to the evaluation function of budgeting (Malmi and Brown 2008; Palermo 2018). Indeed, research has acknowledged that functions of budgeting do not exist in isolation from each other. The resulting constellations may differ greatly. For instance, the varying emphasis placed on planning and on evaluation may account for diverse outcomes in the design of systems of management control (see Hansen et al. 2003). We use the concept of budgetary control systems to refer to implementations that may serve more than one of the functions of budgeting and that represent a wider design of practices around annual budgeting (Flamholtz 1983; Arwidi and Samuelson 1993; Ekholm and Wallin 2000; Otley 2001, 2006). More widely seen, systems that managers use to ensure that the organisational decisions made are in line with certain goals or strategies, can be termed mix-of-controls or management control systems (MCSs) (Merchant and Van der Stede 2007, p. 8; Østergren and Stensaker 2011). By investigating the role of rolling forecasting from the standpoint of various combinations of management control practices and the links between them, we can better understand the diversity in design and use of such control systems. In light of this, we address the following research question: what is the role of rolling forecasting for the planning function of budgeting, and what implications do the way it is used have for management control system design?

To examine rolling forecasting's role in planning and how it ties in with other practices in an MCS, we draw from the recent theoretical work of Tessier and Otley (2012) on the Levers of Control (LoC) framework (Simons 1995), also considering research into the temporal orientation of management control practices (Becker and Messner 2013; Palermo 2018). The conceptualisation by Tessier and Otley, by viewing diagnostic and interactive controls as attention-related attributes of control, aids in drawing a comparison between controls in terms of how they are used. Attention is a key concept also with regard to the time dimension: various attention-directing mechanisms are argued to shape organisational actors' temporal orientations within an MCS (Becker and Messner 2013). This paper examines the role of rolling forecasting in three industrial firms, all of which have recently sought to enhance their planning. While the focus is on short-term planning, evaluation roles are contemplated too, through their linkages to planning. We apply a multiple-case-study approach, which helps us to compare the companies in their MCS design and use. This study contributes to the literature in at least three ways: firstly, it adds new empirical insights to the discussion of the planning function of budgeting and of the role of rolling forecasting in an MCS setting (Hansen et al. 2003; Hansen and Van der Stede 2004; Becker 2014; Becker et al. 2016). Also, our results suggest that certain types of use of rolling forecasting may promote an MCS's proactive functioning (Becker et al. 2016; Palermo 2018). Thirdly, the work increases understanding of how rolling forecasting may complement other practices 
in an MCS and thereby benefit some other functions typically served by budgeting (see Widener 2007; Grabner and Moers 2013).

We begin the presentation by providing conceptual and theoretical orientation, in Sect. 2. This clarifies the design and use aspects of the MCS and presents the theoretical background to our study. The research design and the three case companies are presented in Sect. 3. In Sect. 4, we can then elaborate on the role of forecasting and MCS design in each company, with the aid of concrete illustrations. Section 5 lays out our analysis of the study and details two approaches to how planning may be incorporated into an MCS. A concluding discussion is provided in the final section.

\section{Design and use of a budgetary control system}

\subsection{The design of a budgetary control system}

A problematic aspect of budgeting ${ }^{3}$ is that it can serve various, conflicting purposes (the above-mentioned functions of budgeting), as it might represent a motivational target or the best estimate of expected outcomes available (Emmanuel et al. 1990). Companies have been forced to strike a compromise between these purposes, applying various emphases (Hansen et al. 2003). This has led to problems in using budgets and prompted criticism of conventional practices. Such critique by practitioners has been followed by new developments in budgeting and MCS design, along with various new concepts.

Some radical approaches that focus on the evaluation function of budgeting have culminated in suggestions of eliminating budgets altogether, which is sometimes referred to as budget abandonment (Becker 2014). The concept of non-budgeting exemplifies management control without budgets, along with the absence of negotiated and fixed budget targets in general (see Becker 2014). For example, Beyond Budgeting is a specified template for non-budgeting practice that represents a relatively comprehensive managerial approach to MCS design. In Beyond Budgeting, the target-setting process is separated from the planning (e.g., rolling forecasting) process in respect of contents and timing, and targets are rendered more flexible (Bøgsnes 2009; Østergren and Stensaker 2011; Becker 2014). Advocates of an annual budgeting process, in turn, argue that budgeting increases organisations' efficiency through co-ordination and planning of activities but also helps promote learning and control through comparison of actual results to plans. Bunce et al. (1995) connect the concept of advanced budgeting to use of activity-based budgeting, while better budgeting, which can be positioned as a broad counter-argument in favour of retaining budgeting, encompasses diverse approaches to budgeting, rolling forecasting among them (Neely et al. 2003). The range of practices indicates that the conceptualisation of budgeting practice is far from standardised. However, if we take a wider perspective on an MCS serving various functions typical of budgeting, we can find more common ground among these approaches. Empirical studies have found that practices such as rolling

\footnotetext{
3 We use the term 'budgeting' to refer to the processes of developing and using budgets rather than to a set of numbers these processes may produce that is focused on the amounts of resources allocated among subunits and/or specifies certain performance targets (Covaleski et al. 2003).
} 
forecasting, use of balanced scorecard systems, benchmarking, and target-setting are often used as a complement to budgeting (Ekholm and Wallin 2000; Henttu-Aho and Järvinen 2013). In particular, joint use of annual budgeting and rolling forecasting has been found to be typical in larger and listed companies (Sivabalan et al. 2009). Developments related to priorities may produce diversity in MCS design (see Grabner and Moers 2013), especially since organisations usually aim to design their systems to address the most important problems they face (Hansen 2011). For example, organisations that emphasise the planning function may promote the use of more flexible planning methods, such as rolling forecasting.

The rolling forecasting process offers a systematic mechanism by which an organisation can be forward-looking, in that the tempo of the sequential updates is fast, typically based on monthly or quarterly updates. The horizon of the forecast can vary between 12 and 18 months, but the fundamental idea is that a new month or quarter is added to the plans each time a month or quarter ends. The primary aim for the rolling forecasting process is to facilitate more dynamic and proactive decision-making and it differs from scenario planning by providing estimates only for single points in the future (see Goretzki and Messner 2016; Palermo 2018). Forecasting process is able to focus organisational attention effectively and more universally, which can be explained by its emphasis being on business processes and activities on the ground rather than on cost centres' responsibilities (Østergren and Stensaker 2011, Goretzki 2013). Elements of forecasting may be present in annual budgeting too, though not under that name. In these, the horizon of budget planning is 1 year, and the output is accompanied by formal guidance for the process and tight linkage with the annual evaluation of financial performance (Merchant and Van der Stede 2007). Here, the duration of the budget-related pre-planning process can be extensive, with the work starting four to 6 months before the next fiscal year. Firms may, in fact, update their budgets in the course of the year, via activities that resemble rolling forecasting, but the role of these updates (or de facto rolling budgets) appears ambiguous from the literature. Some studies have found these updates to be used rather more for planning than for evaluation purposes (Umapathy 1987), while others attach them to evaluation and deem their preparation problematic as they create multiple goals (Haka and Krishnan 2005).

From the function perspective, there can be temporal divergence in various respects in the content of planning information between annual budgeting and rolling forecasting. The first difference is related to the pre-period planning stage. Pre-planning has to do with the predetermined courses of action, excluding the monitoring of adherence to them (Chapman 1998). Academic discussion has recently arisen around the content of planning information in relation to the dilemma of whether the business plans prepared are 'target-oriented' or 'realistic' (Østergren and Stensaker 2011; Henttu-Aho and Järvinen 2013; Bourmistrov and Kaarbøe 2013; Becker et al. 2016). The core problem is associated with techniques such as budgets used for planning. That is, if managers are expected to give priority to the evaluation function of budgeting and hence distort the information when providing estimates for the planning, an aggregation of managers' estimates could be suspected to yield a biased outcome. Without this bias, the final plans or forecasts should be able to show 'the picture of a likely and desired future' (Becker et al. 2016, p. 1501) that can sometimes entail revealing (rather than obscuring) the gaps between target and plan (Østergren and Stensaker 
2011). Companies that are oriented toward realistic pre-planning information have been found to monitor the development of forecasting factors and to revise them regularly (Henttu-Aho 2016; Palermo 2018).

The second difference is related to the post-period planning stage, in which the quality and accuracy of plans is monitored through the deviations between planned and realised figures in variance reporting. ${ }^{4}$ In a theoretical sense, if planning is freed of its budget-based performance-evaluation aspect, the accuracy of planning (Hansen et al. 2003) should purely reflect the level of ability to observe changing circumstances. Thus, the amount of accuracy in the forecasting is the amount to which the outcome that was forecast is consistent with the actual outcome. This should remain distinguished from the concept of budget accuracy (Otley 1978; Van der Stede 2000), which refers to how well the budget-related performance targets are met (an evaluative element). Both functional and temporal variations in the planning process influence the use of planning in an MCS.

\subsection{The use of rolling forecasting in a budgetary control system}

Some researchers have noticed that increasing interaction between organisational actors helps to improve accounting information in conditions of uncertainty (Simons 1991; Chapman 1998; Janke et al. 2014). According to Chapman (1998), especially in the pre-planning stage, direct horizontal communication between units within an organisation helps to address complex operational realities and to decrease manipulation of information. In interactive use of control systems, managers devote a significant proportion of their time to management control processes (Bisbe et al. 2007). Intensive use of the control system provides an agenda and forum for regular organisationwide dialogue and frequent opportunities for face-to-face debate at various levels of the organisation (Henri 2006). In particular, budgets and forecasts are used more interactively in volatile business conditions (Janke et al. 2014). Some studies imply that in companies where the planning function is emphasised, the interactive use of rolling forecasting relates to realistic nature of figures (Østergren and Stensaker 2011; Bourmistrov and Kaarbøe 2013; Henttu-Aho 2016). Realistic forecasting entails the organisation's actors being expected to state their actual expectations of future states, in such a way that the persons providing the information are not going to get punished (Bourmistrov and Kaarbøe 2013). This kind of approach means that the evaluation aspect of control is kept separate from forecasting. In rolling forecasting, interactivity manifests itself in many opportunities for cross-profession discussions and possibilities for questioning the information content via discussion (Henttu-Aho 2016). In the interactive use of these systems, the focus is rather more on organisational process than on output (Østergren 2009). This may also support temporal consistency with real-world practices within the organisation instead of pre-specified accounting cycles (Ezzamel and Robson 1995; Ahrens 1997). In particular, an interactive approach

\footnotetext{
${ }^{4}$ Some researchers classify the mechanism of variance analysis as a component of planning that comprises both comparing planned outcomes with realisation and planning remedial actions (Sivabalan et al. 2009; Becker et al. 2016). Even though the concept 'variance analysis' is inextricably interwoven with processes of annual budgeting, a different, though similar, concept—variance reporting-is employed in connection with rolling forecasting (Ekholm and Wallin 2000).
} 
to control systems is argued to focus organisational attention effectively through the intensive managerial use of controls (Tessier and Otley 2012). In light of this, it has been posited that usually only one of the control mechanisms can be used interactively, while others are applied more diagnostically, and that, accordingly, the choice of MCS design is not arbitrary (Simons 1991; Bisbe and Malagueño 2009). Tessier and Otley (2012) have reconceptualised both the interactive and the diagnostic element of the LoC framework (Simons 1995) as attention patterns ${ }^{5}$ of an MCS. This has drawn attention to their benefits with regard to the attention-focusing role in an MCS.

Diagnostic use of a control system is typically associated with post-period planning activities (e.g., when actual performance is compared with predetermined targets for purposes of uncovering critical deviations) (Simons 1995; Abernethy and Brownell 1999). Diagnostic use of control systems follows a mechanistic, repressive, and formal approach to control (Ferreira and Otley 2009). An operation that is effective in the diagnostic use of control systems relies on the supposition that there is accurate and complete reporting of data through formal reporting procedures. It allows managers to monitor the reaching of goals at a distance and exercise management by exception (Simons 1995). However, Mundy (2010) points out another interpretation: regular meetings and discussions about the deviations reported may also involve interactive processes in organisations being useful for seeking opportunities and solutions. Similarly, Janke et al. (2014) conclude that interactive use of a system helps organisation-members to discuss and learn from deviations but also to determine remedial actions for reducing those deviations. These findings indicate possible synergies between interactive and diagnostic approaches to control (Chenhall and Morris 1995; Haas and Kleingeld 1999; Widener 2007). Diagnostic processes can be used to focus attention on exceptions, which, in turn, mobilises interactive processes to increase understanding of the problems (Mundy 2010).

Intensive managerial intervention and various attention-directing mechanisms (e.g., focused on incentives and the nature of information) are able to shape the organisational actors' temporal orientations in the MCS context (Becker and Messner 2013). In particular, in the rolling forecasting process the temporal focus in the managerial intervention and the interactivity level of the approach are expected to affect the nature of the information. For example, if the rolling forecasts are established for five quarters in advance but discussed within the organisation for only the next quarter, people are likely to put their attention and efforts into the coming quarter and not look further (ibid.). Palermo (2018) characterises predictive processes as reactive, proactive, or plausible. In a reactive approach, future-oriented processes use information on the past to look forward. A proactive approach involves utilising future events and factors controllable by knowledgeable actors to capture the 'latest vision of the world' (ibid. p. 17). Systems with plausible predictions do not expect accurate estimates; they rely on narratives, which are selectively used as a basis for evaluation. Becker and Messner (2013) point out that rolling forecasting can change the associated temporal orientation of an organisation. Forecasting is argued to promote proactiveness in organisations via, for example, increasing focus being given to action instead of costs (Østergren

\footnotetext{
5 Meanwhile, Tessier and Otley classify belief systems and both social and technical boundary systems as MCS design attributes. This sets them in contrast against attention attributes, which are seen as operating at other levels of analysis.
} 
and Stensaker 2011), cross-function co-operation being enhanced (Järvenpää 2007), and a forward-looking mindset emerging (Bourmistrov and Kaarbøe 2013). Proactive behaviour can be defined as 'taking initiative in improving current circumstances or creating new ones', which is done by challenging the existing state of affairs (Crant 2000, p. 436). Burkert et al. (2017) argue that MCS design may, through the use of less controllable performance indicators, stimulate more proactive work behaviour, such as intensive communication and greater co-ordination within organisations.

Some recent empirical studies of budgeting have introduced concepts or notions of budgeting styles that appear to point to variability in the role of rolling forecasting in the MCS design. For example, Henttu-Aho and Järvinen (2013) found in their field study of five companies that in the simplified annual budgeting style, the strategybased annual plan played the primary role in planning, control, and evaluation, while rolling forecasting merely supplemented the planning role of budgeting. In contrast, in the Beyond Budgeting style, rolling forecasting was implemented such that it took a major part in planning and the word 'budget' was intentionally avoided. The role of forecasting as distinct from processes serving goal-setting appeared to bring stronger pursuit of realistic forecasts in the pre-planning stage and empowerment of expert functions in the relevant organisation. Sponem and Lambert (2016) identified reactive and proactive budgetary control styles in their survey-based study. The coercive budget represents a reactive style wherein the focus of 'reforecasting' is on diagnostic analyses in the post-period planning stage and this work aids in steering the operations when the initial targets are no longer a reliable benchmark. The interactive budget represents a proactive style in which reforecasts become a central tool in planning, to promote communication about ongoing changes and strategic choices (ibid.). The authors concluded that the frequency of forecasting is not necessarily connected to levels of satisfaction with the budgeting system, as frequent forecasting may end up manifesting either coercive or interactive style.

The various roles of planning are not necessarily related to any particular established technical processes (such as rolling forecasting), and temporal variation in ways of planning may exist even within a given company. Frow et al. (2010) use the concept of continuous budgeting to refer to an organisation's ability to revise plans and allocate resources anew, more flexibly, whether reactively or proactively. The authors point out that controls can be used either diagnostically or interactively, with the application being dependent on the more situation-specific reasons for the deviations or the organisation's circumstances at a particular time. This use is followed by a reassessment of strategic targets if one is needed. Previous studies have underscored that not only the existence of forecasting (or re-planning) but the way in which it is used within the budgetary control system influence the proactiveness or reactiveness of the system.

\section{The research design}

\subsection{Methodology}

The research question on the use of rolling forecasting in planning and its role in an MCS was approached through a multiple-case study examining three industrial 
organisations, all of which are situated in the Finnish paper industry, which has recently encountered several challenges in the industrial business environment and, especially, amid growing global competition. Industrial operations can be identified as an extreme setting (Hansen et al. 2003) in the sense that they represent a field in which increasing market volatility creates pressure for agile planning and structural changes in the players' operations while the production systems demand a long-term perspective on strategic investments. Numerous contextual variables may cause tensions in the design of an MCS in such circumstances. For example, Van der Stede (2000) argues that strategic responses to changing environments may sometimes be incompatible with organisations' size and structure and that this can lead to tensions arising between formal accounting-based controls and more fluid arrangements.

Taking a multiple-case-study approach is seen as an appropriate method for comparing and contrasting the nature of phenomena across contexts (Lillis and Mundy 2005). Multiple-case studies are often situated very close to single-case studies from the perspective of method and methodology. The complexity of the phenomena investigated is typically not as great as with single-case studies, but the approach still enables considering a broad spectrum of research issues and pursuing various aims. According to Scapens (2004), multiple-case-study methods can be used for two purposes: replication and theory refinement. For the first of these, the researcher may select cases that display key similarities, for evaluation of how well empiria supports particular theoretical explanations, while the cases chosen in the latter option (theoretical sampling of cases) might be mutually dissimilar so as to enable drawing conclusions as to the differences and thereby hone or even extend the theory. The initial aim in our research was to select similar cases, for replication: all the paper-industry companies had modified their MCS practices in some respects, and we expected to find a common pattern. However, we found over the course of the study project that the budgeting practice in one of the companies (denoted as company $\mathrm{C}$ ) had moved back toward an annual budgeting process since implementing its changes. This steered our research more in the direction of investigating differences between the case companies and attempting to explain them. We examined the prevailing practices at each company in depth, creating a foundation for extension of the theory as outlined by Eisenhardt (1989).

\subsection{Collection of the data}

Interviews constituted the primary source of data. All told, 22 interviews were carried out, with 24 persons being interviewed, between 2009 and 2014 (see "Appendix 1"). In the exploration of emerging issues, such as new MCS practices, the concepts are not so well established in the literature that they can be studied via survey-based questionnaires. In light of this, interviews were considered an appropriate method for highlighting the type of use and the relationships between purposes or functions typical of budgeting that had not yet been empirically revealed. Indeed, semi-structured and open interviews enabled obtaining a richer picture of the mechanisms operating in MCSs and their interrelation. With our semi-structured interviews in 2009, the aim was to gain information about the then-recent change in budgeting, the role of the 
technical systems involved, the part played by the controller, and any contacts with external consultants. The next interviews, in 2010 and 2011, were focused on providing a map of the linkages between MCS practices but also on the controller's role. The final interviews, carried out in open-ended form in 2014, were designed for forming better understanding of the companies' use and analyses of MCS-originated information.

Since the aim was to collect data on how organisations use the various MCS mechanisms, it was important to collect views from employees at various levels in the organisations. This diverges from the approach typically applied in connection with the LoC framework (Simons 1995), which has directed attention to activities of top managers and to their strategic endeavours (see Tessier and Otley 2012). Because the changes in the companies' budgeting had been found to be closely related to adjustments in the controller role and to new ways of using information in management (Bourmistrov and Kaarbøe 2013; Henttu-Aho 2016), it was deemed important to consider controllers and managers at various levels in the case organisations. This approach afforded a more nuanced understanding of the functioning of MCSs (see Frow et al. 2010). Hence, the focus of the interviews was partly on the controller function (the role of mill, business, and group controllers), while the managerial perspective was captured via interviews with managers at mill and business-organisation level. All the interviews were face-to-face, and each was between half an hour and one and a half hours long. The interviews were audio-recorded, then transcribed in full for analysis. They were supplemented by secondary sources of data: e-mail messages and various publicly available documents, such as annual reports, press releases, and content from the company Web sites. The annual reports were particularly useful for fleshing out the picture. These contained details of the companies' outlook for the future, strategic objectives, and financial goals, which increased our understanding of the business environment and economic situation of the case companies.

\subsection{Data analysis}

The data analysis in the study followed the pattern described by Neuman (2007). Guided by our research question, we began by performing open coding of the data. Our starting point was informed by the budget-related literature's recent highlighting of one function of budgeting as especially important-planning. To identify the mechanisms of planning, we began organising our data in terms of this conceptual category, starting by searching for the elements 'realistic' and/or 'plans'. In addition, we were able to see where these elements were not presented in the data. While we found many methods - such as long-term planning, rolling forecasting, action planning, and annual plans-that fell under these categories at our three case companies, we were able to detect quite early on that there were slight differences across the companies even for each of these. These piqued our curiosity, and we embarked on a more detailed review of the planning methods we had found, to understand how they were used in connection with other controls in the MCS and, in particular, how the planning function of budgeting was arranged. This analysis revealed that some companies talk about 'target-setting' and some about 'budgeting' when dealing with the evaluation function of budgeting. 
The next step in our analysis employed axial coding, for deeper examination of the methods we found and the interrelations among them. Theoretical work on the diagnostic and interactive uses of control systems guided the analysis of MCS practices-we chose this method in the hope that it would help us understand whether a certain type of control-system use could aid in fulfilling some conditions associated with the key functions typical of budgeting. Finally, selective coding advanced our analysis: we were able to focus on specific fundamental methods within the categories of planning and evaluation and construct a theoretical conceptualisation of the complementarities between them in relation to certain types of budget design.

\subsection{An overview of the case companies}

Company A is a publicly traded company. At the time of the study, it had 29,000 employees, in more than 35 countries, worldwide. Most of its production capacity and personnel are in Europe. Sales in 2013 came to 10.5 billion euros. According to the annual report for that year, the company has faced structural challenges in Europe, due to excess capacity in paper production but also significant upheavals wrought by a financial crisis. In response, the company was increasing its capacity in areas wherein demand was experiencing growth, choosing to focus more on growth markets, such as Asia and Latin America. Correspondingly, it sought to reduce capacity where consumption was falling, a goal that demanded better understanding of the key assumptions behind the company's planning. The change in annual budgeting was one consequence of this, but the whole financial-administration organisation was rearranged also.

Company B too is publicly listed. At the time of the study, it employed approximately 21,000 people, worldwide, engaging in production in 14 countries and operating a global sales network. Its sales in 2013 exceeded 10 billion euros. Company B was looking for new growth opportunities through continuous product-development and innovation. In 2013, it adopted a simplified business structure, wherein a specific strategic role and clear targets are defined for each business area. This form of organisation enabled faster decision-making and more differentiated target-setting for the various business areas. The company aimed to improve its short-term profitability via annualised cost savings by the end of 2014, with cost-saving initiatives involving both variable and fixed costs, for all business areas. This company's challenges were rooted in part in the versatility of the business portfolio, which featured mature but also growth businesses. In particular, problems in the mature paper business had increased the need for planning and analysis processes over the years. Simultaneously, some decreases in volumes and prices, along with unfavourable exchange rates, had started causing trouble, with these recent developments prompting efforts toward enhanced planning and various cost reductions.

Finally, company $\mathrm{C}$ is the smallest of the case companies. It is a subsidiary of an international forest-industry group. At the time, that business group had, in total, approximately 11,000 personnel, of whom company $\mathrm{C}$ employed about 900 . The group's sales in 2013 totalled 4.9 billion euros, of which company $\mathrm{C}$ accounted for 1.3 billion euros. According to the business group's annual review for that year, business 
seemed to be on a stable foundation and group-level sales had remained at the previous year's level. The paper operations in which company $\mathrm{C}$ engaged were regarded as traditional in nature; however, the line of business in which company $\mathrm{C}$ specialises is considered highly cyclical, which imposes crucial considerations. Also, the company operates in a global market wherein prices are determined on a monthly basis and, even though shipments can be invoiced for in euros, the prices are negotiated in US dollars. The monthly changes in selling prices and currency risks are continuously discussed between sales staff and customers. Such external, market-based factors can exert a significant influence on planning. Sometimes these changes manifest themselves as large variations in budgets, with substantial deviations between budgeted and actual figures. Among the recent developments were some changes in the company's ownership base: in 2009, company C, which had been owned by two companies, came more clearly into the possession of a single company. This change influenced the budgeting culture and contributed to the re-emergence of conventional budgeting practices in the company.

\section{Planning in the case companies}

This section of the paper reviews the composition of the case companies' MCSs with regard to planning. Working from our initial impressions of the developments that had taken place in the company-specific planning processes, we attempted to ascertain the role of rolling forecasting in the planning and how the companies were employing forecasting to serve MCS purposes more generally. For each case, we describe the methods representing the planning function but also look at their influence on processes serving the evaluation function.

\subsection{Company A}

Interviewees at company A claimed to have abandoned an annual budgeting process. This was evidenced by some interviewees attempting to avoid using the word 'budget' in their speech. Instead they strongly emphasised the role of rolling forecasting, which was seen as an important topic and frequently raised in organisational discussions.

The conventional basis for the planning process in company A was a three- or five-year frame, with updating at a high level in the organisation on a rolling basis twice a year. The updates were presented to the Board of Directors. The focus of the long-term planning was on strategic issues, such as investments, divestments, asset write-offs, and the assessment of these as a whole. The rolling forecasting process served short-term planning in company A, with the forecasts getting updated monthly at mills and further reported upon quarterly. The process gave mill controllers up todate information about price and cost developments. In particular, support functions such as sales, purchasing, and logistics systematically provided information about key forecasting variables (sales volumes and prices, raw-material prices, and freight fees), and the influence of these on each mill's production plans was assessed monthly by the 
mill controllers. According to interviewees, efforts toward realistic plans were clearly increasing.

[W]ith this rolling forecasting, we have a much more realistic view of the future than we would have with a traditional budget, which can be regarded as 'old stuff' [...]. I now dare to use the word 'system' in illustrating that our people really want to do things right and they understand what is right $[\ldots]$. So, in a sense, I'm very pleased with this [forecasting] and I trust in it, even though I understand that there is a risk of psychology sometimes driving people to be target-minded. (Group controller, A, 2011)

Thus, the concept of 'realistic' appeared to indicate a lack of target-orientation, which from a theoretical perspective means that the planning was expected to provide an unbiased estimate of the future level of performance (Emmanuel et al. 1990). The monthly delivery of values for key forecasting variables by various support functions promoted lateral discussion in the organisation. For example, people at the businessarea level of the organisation at company A were able to question the updates to the variables used in forecasting, and, thereby, call into question unrealistic plans.

[I would say] that our forecasting process is really performing well. It is not only a fine document [...]. It is especially important that the forecasts are no longer only prepared by controllers, but these forecasting variables are obtained and discussed within business organisations and we are then facilitating that discussion and process, and also challenging things if it seems that they [other functions] have overly positive expectations. (Business controller, A, 2009)

The group controller at company A saw the increased emphasis on rolling forecasting as having changed mindsets, leading members of the organisation to be more realistic in their plans. No artefacts of the old budgeting culture came to mind that could impinge on the new practices. Under the new approach, controllers appeared to play an especially important role in forecasting.

I would say that at the corporate level, we don't support anything representing remnants of bad budgeting culture [...], for example, if one would make an incorrect accounting entry [...] or neglect to plan actions such that they don't run over budget. We don't have perfect transparency, but I haven't got any indication of that kind of action. Perhaps this rolling forecasting has been able to change the mindset of people, more or less. And I believe that our controller organisation aims to confirm that the forecast is realistic (Group controller, A, 2011)

Instead of a process of annual budgeting, the company now had a separate targetsetting process serving the evaluation function typically performed by budgeting. The process of target-setting can be divided into two parts: one focused on financial targets for various parts of the company and the other on personal targets, where the latter encompassed non-financial measurements also. The main difference between the financial (centred on business-unit evaluation) and personal targets (staff evaluation) was that the personal targets were based more on employees' individual-level responsibilities and could be revised more easily than financial targets (see Sivabalan et al. 2009). In contrast, the financial targets were top-down figures based on the goals 
of the entire corporation and business unit. The top management usually proposed two or three financial targets, which might be connected with indicators such as EBITA, cash flow, and working capital ratio. The target-setting process began each November or December, at which time each year the forecast was updated to provide a financial view of the entire coming year, typically covering five quarters. This snapshot version of the rolling forecast for the next year was frozen and used as a foundation for target-setting and incentives.

In the autumn, when we prepare rolling forecasts and make plans for the whole of the next year, we usually prepare them in more detail. Then some version of the forecasts is frozen and called a budget. It is supposed to serve as a template for our... we talk about a budget or target for the next year. And then incentives are linked to it. (Business manager, A, 2014)

Since we have our figures [the latest 15-month forecast] uploaded in the system, in October we have the outlook for 2010 [the next year]. Then, in November, we prepare our target-setting proposal for 2010, in which we set our targets, and it is important to keep these [two processes] separate. (Group controller, A, 2009)

This so-called frozen forecast method appeared to serve as a link between forecasting and target-setting processes, hence serving not only planning but also the evaluation function. The main aim behind the forecasting was to provide a realistic view of the future, which was seen as functioning as a truthful basis for setting targets in the organisation. The comments by the group controller imply that it was important to keep these processes separate, to avoid creating any bias in the forecasts' figures. Another important pillar of setting short-term goals for the organisation was the long-term planning, through which strategic priorities were communicated.

One interviewee mentioned 'stretched targets', under which a worker could be assigned slightly more demanding operative targets ad hoc. Unrelated to the personal targets set at the beginning of the year, these referred to actions viewed as easy to complete in the near future (for example, in light of the progress already made). Usually, such short-term additions arose from managerial action planning. Thus, action plans $^{6}$ were revised more frequently than before, and details on the realised effects of the planned actions were fed into the company's collaboration platform (i.e., business software), enabling forecasts to be adjusted accordingly.

For example, in rolling forecasting we can state that in 12 months the organisation will have reduced the old inventory by half. If they are able to do this earlier, we can give them a stretched target of eliminating all the old inventory [...]. And at that moment it becomes an issue of action management [...]. Next, if this is deemed feasible, it is included in the next version of the rolling forecast.

(Business controller, A, 2011)

Although fixed financial targets were in place, the flexibility of personal targets could be seen as indicative of non-budgeting practices (Becker 2014). The interviewees at company A did not highlight the issue of variance analysis in evaluation. Rather,

\footnotetext{
6 In this context, the comparing of planned with actual outcomes (variance reporting) and re-planning, to develop remedial actions (action planning), are regarded as components of planning and, in more precise terms, as components of the post-period planning stage.
} 
their primary focus was on reporting of 'planning accuracy'-i.e., deviations between realised and forecast figures and the ability to adapt to changing circumstances (Hansen et al. 2003). In fact, assessment of forecasts and anticipated changes in them had begun guiding the organisation's discussion, action planning, and decision-making. We can conclude that at company A, which claimed to have abandoned its annual process of budgeting, the processes related to forecasting appeared to be acting toward fulfilment of the purpose articulated at the outset-namely, accuracy in planning. Moreover, we could perceive two kinds of convergence between planning and evaluation. Firstly, the forecasting-based tool of the 'frozen forecast' served as a mediating element between rolling forecasting and target-setting, aimed at providing an unbiased basis for setting targets in the company. The lateral process of rolling forecasting was believed to provide a realistic picture of the expected level of performance in the company. The second important aspect of convergence in the MCS was action planning, a managerial process intended to reconcile the information inscribed in annual targets with the most recent plans in the company. Through this mediation, either the plans or the personal targets ultimately get revised, after discussion of the remedial actions necessary.

\subsection{Company B}

When the interviewees at company B spoke of budgeting, they appeared to mean many things: the process of rolling forecasting, budgeting of fixed-type costs, and the target-setting process. When talking about rolling forecasting, they took various perspectives on planning, referring to the latest estimates for the near term, estimates prepared quarterly for the next 12 months, and long-term planning. Though the word 'budgeting' was used, the typical characteristics of annual budgeting — such as budget negotiations, a master budget, and budget-related variance analyses — seemed absent. Interviewees claimed to have abandoned the annual aspect of budgeting in conjunction with the launch of new processes of rolling forecasting.

The informants at company B stressed the aim of accurate and unbiased estimates in the process of rolling forecasting. This was borne out in reality by forecasting variables provided by expert functions, organisational discussions and challenging of the figures.

Whether it's a forecast or a budget, you should never put any slack in there, either downwards or upwards. It should be neither too loose nor too strict. Of course, it always involves a little bit of bias when people are preparing them. But [that bias] must then be cut off by challenging them and discussing [things] with people. (Business controller, B, 2014)

Long-term planning at company B began each spring with strategy work, wherein the top management and strategy team explored the opportunities and challenges, and established a 'strategic will' for the company. This was followed by communication of the strategy and the strategy-implementation process, in which more concrete strategic objectives were set for the organisation as a whole. The time frame for the strategy might be long - for example, 10 years - but more concrete strategic key performance indicators usually were set within a one-to-three-year frame. These top-level objectives 
were then used in the short-term target-setting process in autumn. One important mechanism of the evaluation function was a specific year-end version of the rolling forecast, which was frozen and called a 'plan' or 'budget', to be used for setting targets. The frozen version of the forecast contained a profit-and-loss-form plan for each month in the coming year. The fixed-costs portion of the plan was not readily changed in response to rolling forecasting updates, whereas the variable part was updated regularly.

In the 'budget', we have everything, but what makes the difference is that at the bottom we have fixed costs, depreciation, and investments, the so-called capital components, and [above] we have sales and variable costs. When we prepare the 'budget', we have all these elements there, but the bottom part remains as-is and the upper part changes in line with the forecasting. (CIO, B, 2014)

This polarisation between the elements to the forecast (top and bottom) may reflect industry characteristics. Increasing market volatility in the paper industry has brought greater importance to agile planning of sales and variable costs, yet the production system requires a long-term perspective and more stable view of costs. This kind of juxtaposition was reflected in the division between fixed and variable elements, where changes that emerged between the year-end ('frozen') forecast and further versions of rolling forecasts indicated variance in the upper part of the forecast-i.e., in sales and variable-cost figures (see Van der Stede 2000). In company B, the purpose of the rolling forecasting process with quarterly updates was to reach consensus as to where the company was going to end up within the next 12 months on the present assumptions. There were explicit aims to apply a realistic approach in forecasting without bringing excessively high expectations into it.

In March, when we update our next forecast, we have advanced one quarter forward and we probably already see some movement there. We may have made some new decisions that were not covered in the 'budget'. Over the course of time, when we update our second forecast, in June, the deviations can be bigger, and with the third forecast, in September, the deviations are much bigger. So the 'budget' (based on a frozen forecast) is target-oriented, and the forecast aims to illustrate the situation that we will probably end up in [...]. In rolling forecasting, we look for a realistic outlook on developments in profits, gross margins, and cash flows at the group and business-area levels. (Group controller, B, 2014)

The target-setting process in company B involved company-wide and business-arealevel components but also personally discussed targets involving some degree of negotiation. These could be related to the frozen forecast or to any other metric. Corporate-level targets were usually fixed, whereas at the business-area level, for example, sales organisations' targets could sometimes be altered if major changes in market conditions appeared to have rendered this necessary. According to some interviewees, another mechanism for setting targets that are reachable in rapidly changing circumstances was developed through not fixing them too precisely and allowing managerial action-planning to consider the necessary actions proactively. 
[I]f we, for example, aim to have some level of sales per year, [...] we could set that target at a very detailed level if we wanted to. But from my point of view that is not sensible, since it hinders us from making flexible control decisions. [The objective] is more about having a clear understanding of the target and then, working on the basis of forecasting, contemplating which are the right actions within the limits of the targets. (Business controller, B, 2014)

The variance analysis in company B encompassed comparison both of targets with the actual figures achieved (budget accuracy) and between the forecast figures and the actual figures (planning accuracy) (Van der Stede 2000, Hansen et al. 2003). Assessment of planning accuracy was deemed to be the most important measure in the MCS. Interestingly, analysis of deviation between targets and forecasts was not reported upon systematically.

In summary, while company B claimed to have abandoned its annual process of budgeting in a formal sense, some kind of fixed 'budget' target still existed (see Becker 2014). The accuracy of the forecasting had begun to play an important role. Targets were kept imprecise enough to provide managers with wider discretion to apply forecasting-based information in planning the actions such that the ultimate targets could be reached. It appeared that in company B the processes of rolling forecasting and yearly target-setting were decoupled in the sense of the purpose of each (planning and evaluation, respectively) (Østergren and Stensaker 2011). Convergence between the processes of forecasting and target-setting was evident when forecasts were employed as a realistic template for setting targets, the frozen forecast. Another element of reconciliation was seen in the managerial decision-making and actionplanning, wherein anticipated deviations from forecasts prompted proactive measures actions within the framework of yearly targets.

\subsection{Company C}

Between our rounds of interviews, we could observe gradual change in the budgeting culture at company $\mathrm{C}$. In particular, the change in ownership structure appeared to have led to annual budgeting regaining its status in the company. In fact, some interviewees drew particular attention to the choice of the word 'budget', which they saw as an influential term in organisational management control. In the words of a financial manager at company $\mathrm{C}$, 'the budget is the budget is the budget'. Budgeting was seen as the most important evaluation tool in the company, and rolling forecasting and benchmarking were carried out alongside the budgeting process.

The planning at company $\mathrm{C}$ was performed in accordance with a group timetable and instructions. Strategic long-term planning for the next 3 years was updated in spring, the budgeting process started every autumn, and rolling forecasts were updated quarterly as the year progressed. The executive management team prepared proposed business strategies and budgets to be considered by the Board of Directors. Annual budgeting began in autumn with an assessment of the strategic plans and long-term objectives that had been approved for the company. Working from strategic plans, the company specified key short-term objectives, which were then expressed in action plans and numeric-form budgets. Another fundamental input to the planning was 
the year-end version of the rolling forecast for the next year. Interviewees saw the role of rolling forecasting as being to provide accurate short-term information, but also a realistic view of the company's near future. The company's various departments were not systematically delivering 'forecasting variables', their predictions for such figures as sales (volumes and prices) and raw-material prices, to the control department. Hence, controllers always had to request that information from various function-specific teams. In addition to planning, the role of budgeting encompassed setting targets. The interviewees were keen to highlight the difference in purpose between these two processes, budgeting and forecasting.

The forecast has this short-term perspective. It aims to be realistic, telling how it [all] looks. But in the budgeting we want to set some specific levels of volumes and prices and then, accordingly, the level of costs. [Budgeting] really is more target-oriented. (Controller, C, 2014)

Interestingly, one interviewee placed emphasis on the unified nature of these two control elements. Indeed, it was impossible to draw a line between forecasting and budgeting and thereby delineate either main process or the organisational actors within that process. Scholars see an integrated process of this sort as entailing a risk of managers giving a target-oriented twist to their 'forecasting' (Østergren and Stensaker 2011). Processes of rolling forecasting and budgeting appeared to be clearly interdependent and ultimately represent the same level of detail in the information content.

We have a uniform process [across the two]. The same actors but also the same system and process. Forecasting is rolling in this way, and the budget is actually only one version of the forecasting that we then take [for budget use] [...]. They [the budget and forecast] have the same detail. The forecast has the same extent of information as well. (Controller, C, 2014)

In preparation of the following year's budget (sometime in October), one version of the rolling forecast was modified to be used as a budget. This procedure appeared to have implications for the main principles applied in forecasting. According to some interviewees, the aim of producing realistic figures in forecasting was de-emphasised at the time of budget-preparation, and the year-end version of the forecast was prepared so as to be more target-oriented.

Our budget is one version of the forecast, which has been frozen [...]. Actually, it [the budget version of the forecast] is prepared at a more detailed level than other versions of the forecast [...]. It is also slightly more target-oriented. That is the key difference. (Controller, C, 2011)

This kind of target-orientation leads one to wonder about the possibility of actors adding bias to the plans. According to the lead financial manager of company $\mathrm{C}$, the target-orientation meant that the forecast was prepared in accordance with corporate instructions to produce a realistic plan without any slack yet in a manner reflecting an ideal/assumption of continuous improvement. For example, the sales volumes were always planned to be slightly higher than the previous year's but still achievable. An additional part of the picture is that the corporate management made any final decisions on major revisions related to the next year's market outlook. 
There were several formal elements in place for budgeting, such as guidelines for the process, a master-budget-type summary, and official approval from the Board of Directors. Budget targets were compiled mostly on a top-down basis, but in practice there were bottom-up elements too. Annual budgeting at company $\mathrm{C}$ was supplemented with benchmarking, which appeared to serve as an operational tool for comparing performance across various mills and actually represented application of a relative performance standard in the budgeting process (Hansen et al. 2003). The core element of the budgetary control system was the variance analysis, viewed as the most important and most formal reporting tool in company $\mathrm{C}$. The variance analysis report was established as a part of the monthly reporting package. Deviations between budgeted and realised amounts and also between forecast and actual figures were reported. Because the forecasts and budgets presented the same level of detail, it was possible to go further, analysing the variance between forecast and budgeted amounts as well.

Variance analysis is one of the most important tools [...]. It is a control tool, and it tells us in particular the reasons for variances, rather than about the existence of variances. And then we start to inspect them in more detail case by case [...]. Is it because of the timetable, difference in prices, or need for investments? (CFO, C, 2014)

Volatility in product prices and fluctuation of exchange rates created particular risks for this business. Since the variances stemming from larger market forces were ultimately beyond the company's control, the company found it important to concentrate its efforts on things actually influenced by the internal decision-making. While not placing so much focus on these uncontrollable factors, company $\mathrm{C}$ did prepare some sensitivity analyses on the basis of them-for instance, examining anticipated price variations for purposes of better understanding the consequences of certain price levels for profits. Meanwhile, more controllable factors (such as personnel costs and support-material costs) were amenable to accurate budgeting.

We can summarise the situation of company $C$ thus: the annual budgeting was central to the budgetary control system, with great emphasis being placed on the evaluation function of budgeting. This was strengthened by intense use of variance analysis reporting to generate new actions in support of the goals set earlier. In company $\mathrm{C}$, the variance analysis served as a formal mechanism that was routinely employed as the foundation to the planning of new actions. The role of forecasting was to confer some sense of a realistic outlook on the future state of affairs, but a more important effect is that it appeared to support the annual budgeting process in its aims of planning and evaluation.

When one examines the interviewees' accounts of budgeting at the three case companies side by side, it proves illuminating that the interviewees at companies A and B felt that they had abandoned budgeting in its traditional form (i.e., an annual budgeting process), with company A personnel's efforts to avoid even the word 'budget' being particularly noteworthy. In contrast, employees at company $\mathrm{C}$ stressed the literal meaning of the word 'budget', which reflected the continuing use of budgets and the value accorded to the evaluation function of budgeting. This kind of rhetoric appeared consistent with the design of the budgetary control system. In company $\mathrm{C}$, forecasting was strongly connected with annual budgeting. Another finding is that companies 
A and B stressed accurate follow-up in response to increasing market volatility, and the separate processes of forecasting and target-setting were kept more faithfully in line with their initial purposes, which has been found to be a distinctive feature of non-budgeting practices (Østergren and Stensaker 2011; Becker 2014).

Next, we will discuss the differences among the MCSs in our three case companies from the perspective of diagnostic and interactive use of controls. Investigating the difference in application of control elements may uncover why differences in emphasis with regard to the individual functions of budgeting within an MCS can produce different approaches to environmental uncertainties.

\section{Reactive and proactive types of control system}

The foregoing discussion illustrates that the role of the planning function displays some variability through the use of rolling forecasting in MCS design. An important question arises in relation to how companies in systems of this sort reconcile the prospects for the future with the organisation's goals, analyse the reasons for possible gaps, and re-plan to generate remedial actions. We will now consider the MCS design ramifications of the way in which rolling forecasting is used. To do so, we classify the case companies as representing either reactive or proactive systems, on the basis of their approach to planning (see Palermo 2018). The findings related to these types of control systems are presented in tabular form in "Appendix 2". The table differentiates among the various characteristics of design and use in each of the case companies, which underpin their classification as having either reactive- or proactive-type MCS use.

\subsection{Reactive planning in a budgetary control system}

In company $\mathrm{C}$, the annual budgeting process and monitoring of deviations between actual, forecast, and target figures were emphasised. Variance analysis was seen as the most important reporting and management control tool. With regard to how the MCS was used, the company's variance analysis appeared to signify a diagnostic approach (Simons 1995), as its focus was strongly on numeric expression and exceptions. We found the business steering to be based on formal assessment of numerical budgetary variances, which then triggered remedial actions.

We have created some predefined report templates in the system, to enable running an updated version of variance analyses. The system provides us with accurate information about the deviations in quantities, consumption, and prices. We can directly see the variances in relation to actual figures or the budget and are able to start remedial actions. We also revise the forecast, if that is needed. (Group controller, C, 2014)

In company $\mathrm{C}$, the exceptions were reported upon in great detail. Reports gave information on deviations by cost type and by business unit and mill. The figures achieved were compared to the budget, but also the forecast for the accounting period was 
compared to the budget. In addition to getting reviewed monthly in the meetings of the executive- and the production-management team, variances were examined at controller meetings. Furthermore, variance analyses were followed by discussions at regular review meetings held at each mill, where the appropriate actions were planned, assigned, and timetabled. It is worth noting that such meetings and discussions about the figures can incorporate some aspects of interactive processes (Mundy 2010).

We have regular review meetings at every mill, where we look at these variances and then plan some actions in accordance with them. We share the responsibilities, plan the timetables, and follow the implementation of action points to see that they really are put into practice. (Group controller, C, 2014)

An additional element supporting the budgetary process at company $\mathrm{C}$ was the holding of ad hoc top-management meetings. This helped the small group of managers obtain an overview of the near-future market situation and decide whether a need existed for any strategically important short-term moves, such as altering the timing of sales in the wake of low prices or finding new customers. ${ }^{7}$ As this practice concerned a very limited group of people, it did not indicate an interactive approach so much.

[This] is not about [high-level] corporate control; rather, it is an issue of shortterm profit forecasting, one month or the current quarter, prepared within the business [company $\mathrm{C}$ ]. The sales management, financial management, top management, and production management together assess what is our best... what in German is called the fingerspitzengefiuhl [the feel] of the situation [...]. Then we can inform the corporate management about our best forecast for this quarter and can plan to take some strategically important short-term actions monthly. However, we have to have flexible tools to see how the markets are developing. (CFO, C, 2014)

Nevertheless, the emphasis in the budgetary control system at company $\mathrm{C}$ was on reaching the predefined targets. There was some ambiguity as to the position of rolling forecasting. The CFO pointed out that in principle the forecast was regarded as a revision of a budget. When Sponem and Lambert (2016) use the term 'budget revision', they mean that the initial budget targets are changed, but their concept of budget reforecasts may work better in this context, denoting updates to budget information. At the same time, some controllers saw the forecasting as an important tool for providing a realistic outlook. This ambiguity as to the role of rolling forecasting could have some connection with the changes in budgetary practices that had been implemented in company $\mathrm{C}$, with mixing of ideas related to budgetary practice. It is possible that the role of rolling forecasting expressed by the CFO reflects the status recently accorded to annual budgeting in the corporation by its senior management, while the role it had for other members of the organisation amid the ongoing shift in budgetary practices may have formed an altogether different part of a complexities landscape (Samuelson 1986).

\footnotetext{
7 The selling price was usually a given factor for the paper company, which operated in more competitive global markets. Therefore, the main options in conditions of declining sales prices were to reduce inventory levels via one-off sales of larger lots to a single customer and to wait for prices to go up rather than sell at lower rates.
} 
That said, the role of forecasting in company $\mathrm{C}$ may not be so surprising and can be partly explained by the interplay of controllable and uncontrollable business factors. In particular, market factors such as variation in product prices and fluctuation of exchange rates could not be easily predicted; sensitivity analyses for price variations were found more helpful than attempts at prediction. Moreover, controllable factors such as fixed costs were argued to be easy to budget. These findings gain support from the fact that in the pre-period planning stage of rolling forecasting the staff of company $\mathrm{C}$ were not actively supporting generation of rolling forecasting assumptions through systematic delivery of forecast-input variables. In line with Palermo's thinking (2018), as the company was not effectively investigating factors underlying the forecasts, the system should not be deemed proactive.

In company $\mathrm{C}$, the forecasting was closely linked to the budget at all times. Regarded as a revision to a target-oriented budget, it was not conceived of very much as the independent, separate process of planning that recent management control literature depicts with regard to the aim of providing a realistic outlook for planning (Østergren and Stensaker 2011).

[The budget] is a kind of crystallised view by the management. And, by accepting it, the Board of Directors becomes committed to the direction of it. This is what we believe in. And the company management are then provided with the freedom to [find ways to] implement that next-year plan. But we live in a changing world [...]. We have to have tools such as forecasting to change the direction of our actions. But it is still about checking whether we are heading to the right direction of the budget. The budget is always the basis, as we planned. Sometimes we follow the budget in great detail, and sometimes we have to take steps in another direction. (CFO, C, 2014)

Budgetary variance analysis at that company appeared to have been used in primarily a diagnostic manner-i.e., for indicating which matters the company must centre its efforts on if it wishes to achieve its goals. One hallmark of this kind of MCS is related to the concept of budget accuracy (Otley 1978). It was apparent that the emphasis in company $\mathrm{C}$ was on meeting the budgetary targets and that success in doing so was monitored by means of the variance analysis tool. Deviations were indications of low budget accuracy, and planning tools such as forecasting were explicitly used to minimise deviations and increase the accuracy of the budget. We can conclude that a diagnostically oriented focus on budget accuracy of the sort seen at company $\mathrm{C}$, represents a reactive approach to planning, with the calculated deviations providing an impetus for starting to plan rectifying actions (Palermo 2018). In a theoretical sense, because the business seemed to be on stable footing, it was natural for an emphasis on diagnostic use to be viewed as beneficial for the company.

\subsection{Proactive planning in a control system}

In companies $\mathrm{A}$ and $\mathrm{B}$, the variance analysis was not used in a formal manner. In the absence of a unified annual budgeting process, the deviations were reported upon regularly but still contemplated more interactively. Emsley (2001) calls this kind of 
approach an 'informal system of variance analysis'. Strivings toward preparing more realistic forecasts generated a situation wherein processes of yearly target-setting and rolling forecasting were decoupled in the sense of their purposes. The operational focus was clearly on frequently updated forecasts and on forecasting (planning) accuracy (Hansen et al. 2003). Importantly, the aim of realism in forecasting was reinforced by interactive elements, discussion, and challenging of the figures. Usually, the discussions related to deviations were intended to generate ideas for remedial actions in various meetings.

One major change is related to our strong forecasting process, where the emphasis is on discussing future issues. When we receive the information about the profit, we usually just observe the actualised level of it, and if there is some deviation, we ask why. We use $20 \%$ of our time for observing that, and then $80 \%$ of the time we discuss the future and what actions we should take in order to confirm the reaching of our goals. (Business controller, A, 2011)

While these discussions represent an informal and non-technical control system, they were difficult to characterise further. The discussions were sometimes referred to as 'action planning', and at both companies A and B they were considered to be inherent to the entire forecasting process. This dynamic action-planning was manifested clearly at monthly review meetings at which those documented action plans that had been included in updated forecasts were discussed. Moreover, new remedial actions were suggested. In fact, the action-planning involved continuous discussions among managers and controllers at various levels of the organisation. This is in line with Frow et al.'s (2010) description of 'continuous budgeting', as various managers were constantly engaged in reviewing their performance in relation to their targets and what needed to be done.

Everyone transparently sees all the necessary information, and it will be discussed [...]. The point is not that you get some responsibilities and you get some reports but that people sit down around the same table and discuss the figures and the direction of the business. (Business manager, A, 2014)

We have a monthly performance review, where we review the performance for the previous month [...]. Business-area people are producing that information [...], and if there are some big deviations, it will generate some actions. Those actions are then discussed and challenged at the business-area level, and thus it is very iterative. Because the world changes frequently, it has to be that way. (Business controller, B, 2014)

These extracts indicate that the way in which the MCS was managerially used at companies A and B was quite interactive (see Tessier and Otley 2012) and involved many social elements (Mundy 2010). This might be related to the strong emphasis on forecasting and its realistic nature, which needs to be supported by means of interactive elements of control. For example, the way in which the organisational actors were able to challenge whether forecast figures were realistic or not established a social boundary system (a design attribute of an MCS) in the organisation (Simons 1995; Tessier and Otley 2012) and could be seen mitigating the individuals desire to inject bias into plans. 
The quotations indicate that in companies $\mathrm{A}$ and $\mathrm{B}$, the deviations between forecast and actual figures but also between targeted and actualised figures were typically examined via separate reports. Interestingly, the deviations between forecasts and targets were not monitored through formal reports in company B as they were in company $\mathrm{C}$, since the former applied many kinds of targets, which were not at such detail-oriented level as the forecasts.

[Forecast vs. actual] should be the realistic view of performance and the other [target vs. actual] what we aim for but don't expect to achieve every [single] month. There is a difference. The forecasting is prepared at a high level of precision, but the target-setting is not so detailed, and you can't make as detailed a breakdown as in the forecast. (Business controller, B, 2014)

The assessment of deviations between targets and forecast was based on managerial understanding of the key goals of the business and close monitoring of developments in business. Following the approach of Goretzki and Messner (2016), one can see that the assessment of the need for remedial actions was based on managers' ability to create a common understanding of the current and future situation.

Actually, those who look at the forecast [...] already have in their minds the targets set for that business area. There is no need to prepare presentation material where target and related forecast figures are presented. People know what their targets are, and then they just analyse the situation and outlook for the near future [...]. That gives a signal of the near-future prospects. (Group level controller, B, 2014)

In actuality, the necessary actions were usually performed or incorporated into the forecast long before their effects could be known in monetary terms. This illustrates the 'proactive' nature of management control wherein strong emphasis is placed on systematic delivery of forecasting variables in the pre-period planning stage, anticipatory discussions at various levels of the organisation, and measures taken well in advance (Palermo 2018).

For example, if our performance does not match the forecast, we often know beforehand the reasons we are not able to get there. At the point when we calculate the deviation between forecast and actual, we will only verify our prior knowledge in financial terms [...]. Often, the actions needed are already in progress when we start to assess the effects of deviation in monetary terms. (Business controller, B, 2014)

From our findings we suggest that this kind of interactive approach to an MCS, wherein rolling forecasting is given strong emphasis in pre-period planning stage, could be seen as representing a proactive type of planning in an MCS. In a situation of global overproduction of paper and increasing market fluctuations, this kind of design and use of an MCS seems reasonable, because it not only enables anticipation of environmental contingencies (Arwidi and Samuelson 1993) but also provides sensitivity and flexibility in MCS use.

Figure 1 provides a theoretical presentation of a proactive type of MCS wherein the planning function is emphasised. The processes of forecasting and target-setting 


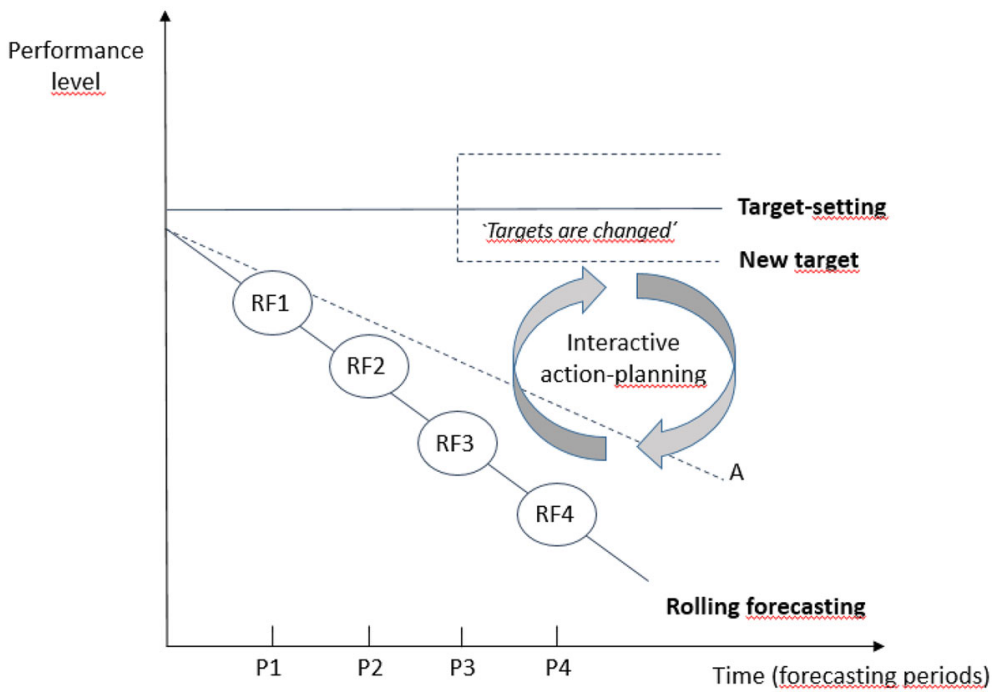

Fig. 1 Proactive-type planning in a management control system

each follow their own purposes and are sufficiently separate from each other as processes (as seen in companies A and B). This kind of setting promotes an interactive approach, while the deviations between targets and forecasts are not necessarily formally reported, on account of the differences in accuracy and temporal focus between these sets of figures.

In Fig. 1, the target-setting process utilises one version of the forecast as a basis for targets by compiling the strategic-level targets within that forecast. This yearend snapshot version of the next year's forecast is referred to by some as a frozen forecast. Hence, at the beginning of the year there is a controlled relationship between forecasting and target-setting, as the forecast is equivalent to the frozen-forecast-based 'budget', upon which basis appropriate targets are set. However, as the year progresses, the gap between the flexible forecast (the lower portion) and more stable targets (the upper part) may widen, since the new versions of the forecast (RF1, RF2, etc.) are designed to reflect the changes in the business environment. The diagram in Fig. 1 is consistent with the theoretical conclusion by Otley (1987) that if the target (from the upper part) is expected to lead to the best possible level of outcome, it must be set to be better than the level likely to be achieved (the lower, forecasting-based part). At the same time, a gap is a signal to the management to identify possible remedial actions, in order to get the forecast line to approach the target line again (represented by dashed line A). If, however, the targets appear to be unrealistic because of major changes in the business environment or structural changes, there may be a need for a mid-year revision of the targets (represented by the 'New target' dashed line) via, for example, stretched targets. 


\section{Concluding discussion}

Recent research has started to emphasise a function-oriented view of control systems and techniques. For example, some new accounting tools such as rolling forecasting are known to be entering increasing use for a planning function formerly fulfilled by budgeting. However, we still lack empirical understanding of how rolling forecasting is incorporated into MCSs. Forecasting might play different roles in connection with an annual budgeting process or in connection with another mix of controls in an organisation. Therefore, in our study, which focused on traditional companies in the paper industry, we investigated how companies differ in their ways of using rolling forecasting in their planning and what implications these choices have with regard to their MCS design. For its theoretical grounding, the study draws on refined definitions of diagnostic and interactive control systems that emphasise the aspect of controlsystem use (Simons 1995; Tessier and Otley 2012) and the temporal orientation of management control practices (Becker and Messner 2013; Palermo 2018).

In the multiple-case study, it appeared that the three companies examined were using very similar tools to accomplish the key functions typical of budgeting. All of the companies had a process of strategic planning in place that provided key goals for target-setting. Short-term planning was present in the process of rolling forecasting. In each company, target-setting was somehow linked to a year-end version of rolling forecasting (a frozen forecast), from which the targets were set. However, there were differences between the companies in how they emphasised rolling forecasting, which then influenced the use of the control system.

The study contributes to the literature in three ways. Firstly, it responds to calls in the literature to combine a function-oriented view with a more disaggregated MCS approach (Sivabalan et al. 2009; Becker et al. 2016). Instead of a unified system, a budgetary control system can be seen as a subdivided system wherein various management control items, forecasting among them, fill various budgetary functions. In fact, we found two types of use of rolling forecasting to serve an MCS planning function, where the emphasis in planning displayed differences in temporal orientation (Palermo 2018). One involved a reactive type of planning, seen in one of the case companies. In that kind of system, rolling forecasting and annual budgeting are integrated, forming a unified process serving planning and evaluation tasks, with emphasis on the evaluation function. This kind of hybrid system has been found to be commonplace among adopters of rolling forecasts (Ekholm and Wallin 2000; Sivabalan et al. 2009). This may be explained by our finding that the hybrid use creates an ability to use the same resources and procedures throughout the organisation. In the case company, the joint process of forecasting and budgeting was carried out by one set of people, and the two aspects displayed the same detail of information throughout the process. In that kind of system, variance analysis means a formal calculation of deviations between actual, budgeted, and forecast figures, where the feedback then triggers remedial actions (via exceptions-based diagnostics) (Mundy 2010). Applying the same level of detail in forecasting and budgeting enabled diagnostic monitoring of uncontrollable factors and more stable fixed costs through a variance analysis report, on which basis operational re-planning and solving of problems could be made ex post (Emsley 2001). The focus of forecasting in a reactive approach is clearly on the post-period planning 
stage: reporting of variances and planning of remedial actions. This MCS approach is based on recognisable temporal cycles, in which procedures of planning can be clearly identified and defined (Palermo 2018).

The other type of forecasting used was a proactive type of planning approach, presenting itself in two of the case companies. In this kind of approach, the planning function was strongly emphasised, generating a situation wherein the yearly targetsetting process and rolling forecasting were decoupled in the sense of purposes. In academic and practice-oriented literature, this separation of control processes on the basis of their purposes is already evident in relation to so-called non-budgeting practices (Becker 2014; Bøgsnes 2009; Østergren and Stensaker 2011). The findings of our study show that this kind of approach enables proactive steering of business. As organisational attention is on the pre-period planning stage of forecasting, information about the future contingencies is more readily available and more closely reflects changes in environmental conditions (Palermo 2018). Interestingly, the deviations between forecasts and targets were not reported formally in our data, while the targets were not set at as precise a level as that used in the forecasts. Therefore, interactive process aspects such as short-term action-planning, continuous organisational discussions, and transparency of information appeared to play a crucial role in helping assess the extent of gaps between the targets and future prospects in two of the case companies, but it also generated flexibility within the system (Frow et al. 2010; Mundy 2010). Actually, if we consider Palermo's discussion again (2018), from the MCS angle the proactiveness here means not only producing more proactive information for planning but also taking actions proactively in light of that information (i.e., the necessary actions were usually performed much earlier than when the associated effects were known in monetary terms). The findings from our study indicate that traditional types of monitoring variances (formal reports based on detailed calculations of deviations etc.) do not necessarily encourage flexible planning. This supports the conclusions of Emsley (2001), who points out that waiting until evidence of deviations has accumulated may not be justifiable; on account of the delay, following the planned actions may lead to worse performance. The key characteristics of reactive and proactive approaches in relation to the three case companies can be found characterised in "Appendix 2".

The second contribution of the study is related to the emphasised role of planning in MCSs. Becker et al. (2016) state that organisations wishing to reduce their environmental uncertainty aim to execute more accurate planning. Our findings suggest that various emphases on functions typical of budgeting may differ in the kinds of use of control systems they necessitate. For example, the aim of realistic plans in forecasting (planning) could be promoted via an interactive approach in the pre-planning stage and systematic delivery of forecasting variables (Bourmistrov and Kaarbøe 2013). It is evident that the interactive use of controls increases the amount of information available (Østergren 2009), but we found also that it can improve the quality of accounting information. Our findings indicate that interactive use of control systems helps to challenge underlying assumptions behind forecasting information (the forecasting variables) held and conveyed by various organisational actors and thereby increase the realistic orientation of the information. This kind of information is considered highly important in a proactive approach (Palermo 2018). Discussions at various levels of the organisation and challenging the providers of forecasting information 
assisted our case companies in increasing the production of figures that were realistic overall for forecasts and reducing the possibility of bias in the forecast figures. This is in line with the work of Sponem and Lambert (2016), who state that the interactive budgeting style is also 'a state of mind to be shared with all collaborators'. Such activity is related to a process of socialisation wherein organisational actors assimilate new values from the management control practices (see Alvesson and Kärreman 2004). Our findings indicate that the 'preparing of realistic plans' was an important organisational value that employees were supposed to have adopted and thus could be regarded as representing a belief system (Simons 1995). While Tessier and Otley (2012) classify a belief system as a design attribute of an MCS, our study actually shows how specific value accorded to some budgetary function strongly affects the way in which the system is designed and, in particular, how it is used.

The third contribution of this study lies in our suggestion of using forecasts as a readily communicated basis for setting operative targets, our findings provide support for the idea that making forecasting a part of an MCS may be beneficial (Malmi and Brown 2008). We found that interactively prepared forecasts were able to serve as a realistic template (via the frozen forecast) for the year-end target-setting process. As we pointed out earlier, decoupling the processes of forecasting and target-setting, particularly in the sense of their purposes, is vital, yet from the viewpoint of technical processes they were interdependent and supporting the idea of a system (Grabner and Moers 2013). Sponem and Lambert (2016) imply that the synergies between practices fulfilling the planning and control functions of budgeting can reduce the criticism levelled at budgeting. At all three case companies, one important basis for the target-setting was the year-end version of rolling forecasting for the next year, upon which basis the challenging targets were supposed to be set. In the process of target-setting, the forecasts informed managers of the outcome level that was likely to be reachable and therefore served as a prerequisite for motivational targets (see Otley 1987). This finding is consistent with the study of Widener (2007), nicely displaying the complementarities between interactive plans and diagnostic evaluation practices in budgeting. However, in a contrast against what has been suggested in earlier work, we found evidence that the interactive use of a particular management control item can actually lead to benefits in the diagnostic use of another management control item (Widener 2007; Mundy 2010).

Budgeting research in the accounting field has emphasised the role of negotiations in revealing the information needed about subordinates' performance capabilities (Fisher et al. 2000). Our empirical findings indicate that in new arrangements of MCSs the forecasting process may play an important role in efforts to provide a realistic benchmark speaking to the expected level of future performance. Formal budget negotiations are not necessarily needed for informing supervisors about what constitutes a realistic level of performance in relation to which more challenging targets can be set (Fisher et al. 2000). Note, however, that this kind of arrangement is not equivalent to a situation wherein the supervisor unilaterally sets the goal. The forecasting process (providing a template for target-setting) appeared to represent a more horizontal management control process in some of the case organisations. This finding increases our understanding of budgeting and non-budgeting practices in relation to formal negotiations and fixed targets (Becker 2014), and the possibility that the diminishing role of for- 
mal budget negotiations and the use of less rigid budget targets actually make budget abandonment easier deserves further study.

Finally, our study goes some way to answering Emsley's call (2001) to consider how the different elements of the MCS theoretically interact and jointly operate. The study provides an illustration of the proactive approach to incorporating rolling forecasting into an MCS. The illustration in Fig. 1 explains the points of similarity and discrepancies between forecasting and target-setting from a technical and an MCS perspective alike. It shows that the processes and perspectives of forecasting and target-setting have a relatively controlled relationship at the beginning of the year, after which planning diverges strongly toward its initial purpose-accuracy of planning (see Hansen et al. 2003). The gap between the lines representing forecasting and target-setting provide a space for informal control mechanisms, geared either for triggering remedial actions and new plans or, occasionally, responding to the need for departure from the initial targets.

A more practice-oriented implication of the study is that these more flexible MCSs can be useful for companies that not only operate in heavy industry involving high capital-intensity but also face increasing market volatility. For example, the estimate figures at the top of the forecast template (sales figures and variable costs) can be updated more often than the more stable fixed costs, addressed in the lower section. Also, clearer separation between forecasting and target-setting processes may enable companies in this branch of industry (such as A and B) to adjust as needed. They may set fairly stable strategy-based targets while retaining a more flexible process for planning (Hansen et al. 2003). When a large proportion of the variance that affects plans is related to uncontrollable market factors, forecasting may not be emphasised in planning, since controllable factors such as fixed costs can also be budgeted more easily (company $\mathrm{C}$ ).

One limitation of multiple-case studies lies in the detail of empirical description. Not all of the interesting findings can be investigated and analysed in detail. They remain to be examined by means of a single-case-study approach, which provides ability to obtain deeper insight into the social mechanisms. Our intriguing finding that companies may use one version of the forecast as a basis for setting targets raises a question of possible bias in producing the coming year's version of the forecast. A critical and more detailed approach employed in a single-case study might provide valuable information about the mechanisms that might prevent or mitigate biasing of forecasts, along with insights pertaining to dysfunctional effects of setting targets on the basis of forecasting. In a final comment regarding avenues for future research, we should state that the function-based approach to MCSs in combination with new complementary elements in budgeting warrants more research. For example, in relation to the evaluation function of budgeting, research has introduced many interesting tools, such as balanced scorecards and benchmarking. It would be important to investigate empirically how the widely criticised evaluation function of budgeting might benefit from these new tools and how they might be incorporated into other instruments in an MCS context.

Acknowledgements Open access funding provided by University of Oulu including Oulu University Hospital. The author gratefully acknowledges the helpful suggestions and comments provided on earlier versions 
of this paper by Erik Strauß, Caroline Lambert, Katarina Kaarbøe, Geraldine Robbins, Sinikka Moilanen, and Janne Järvinen and by the journal's two anonymous reviewers. The author is thankful also for feedback from attendees of the 2016 research seminar at the NHH in Bergen and the 10th ENROAC Conference, in Galway, in 2015. In addition, financial support received from the University of Oulu Graduate School doctoral programme is gratefully acknowledged.

Open Access This article is distributed under the terms of the Creative Commons Attribution 4.0 International License (http://creativecommons.org/licenses/by/4.0/), which permits unrestricted use, distribution, and reproduction in any medium, provided you give appropriate credit to the original author(s) and the source, provide a link to the Creative Commons license, and indicate if changes were made.

\section{Appendix 1}

Details of the interviews at the three case companies

\begin{tabular}{|c|c|c|c|}
\hline Case firm & Interviewee position & Interview date & Duration \\
\hline A & Business controller & 26 Oct. 2009 & $1 \mathrm{~h} 13 \mathrm{~min}$ \\
\hline A & Group controller & 2 Oct. 2009 & $57 \mathrm{~min}$ \\
\hline A & Newly appointed group controller & 6 Jun. 2011 & $1 \mathrm{~h} 23 \mathrm{~min}$ \\
\hline A & Business controller & 6 Jun. 2011 & $1 \mathrm{~h} 8 \mathrm{~min}$ \\
\hline A & Business controller & 7 Jun. 2011 & $1 \mathrm{~h} 10 \mathrm{~min}$ \\
\hline A & Mill controller & 9 Aug. 2011 & $1 \mathrm{~h} 2 \mathrm{~min}$ \\
\hline A & Mill controller & 11 Apr. 2014 & $36 \min$ \\
\hline A & $\begin{array}{l}\text { Mill director, operations manager, and regional controller ( } 3 \\
\text { persons) }\end{array}$ & 11 Apr. 2014 & $45 \mathrm{~min}$ \\
\hline A & Business manager & 26 May 2014 & $59 \mathrm{~min}$ \\
\hline B & Business controller & 1 Oct. 2009 & $1 \mathrm{~h} 24 \mathrm{~min}$ \\
\hline B & Group controller & 1 Oct. 2009 & $1 \mathrm{~h} 23 \mathrm{~min}$ \\
\hline B & Sales controller & 1 Oct. 2009 & $42 \mathrm{~min}$ \\
\hline B & $\mathrm{CIO}$ & 19 Apr. 2010 & $1 \mathrm{~h} 5 \mathrm{~min}$ \\
\hline B & Group-level controller & 15 May 2014 & $1 \mathrm{~h} 25 \mathrm{~min}$ \\
\hline B & Business controller & 15 May 2014 & $1 \mathrm{~h} 24 \mathrm{~min}$ \\
\hline B & $\mathrm{CIO}$ & 16 May 2014 & $1 \mathrm{~h} 10 \mathrm{~min}$ \\
\hline $\mathrm{C}$ & Mill controller & 10 Sept. 2009 & $36 \mathrm{~min}$ \\
\hline $\mathrm{C}$ & Business controller & 15 Dec. 2009 & $1 \mathrm{~h} 3 \mathrm{~min}$ \\
\hline $\mathrm{C}$ & Business controller & 9 Nov. 2011 & $39 \min$ \\
\hline $\mathrm{C}$ & Business controller & 26 May 2014 & $52 \mathrm{~min}$ \\
\hline $\mathrm{C}$ & Group controller & 26 May 2014 & $1 \mathrm{~h} 24 \mathrm{~min}$ \\
\hline $\mathrm{C}$ & $\mathrm{CFO}$ & 27 May 2014 & $49 \mathrm{~min}$ \\
\hline \multicolumn{2}{|c|}{ Persons interviewed } & 24 & \\
\hline \multicolumn{2}{|c|}{ Number of interviews } & 22 & \\
\hline
\end{tabular}




\section{Appendix 2}

Reactive or proactive types of planning in MCS

\begin{tabular}{|c|c|c|c|}
\hline Attributes & $\begin{array}{l}\text { Company A } \\
\text { Proactive }\end{array}$ & $\begin{array}{l}\text { Company B } \\
\text { Proactive }\end{array}$ & $\begin{array}{l}\text { Company C } \\
\text { Reactive }\end{array}$ \\
\hline \multicolumn{4}{|l|}{ Design } \\
\hline Status of budgeting & Non-budgeting talk & $\begin{array}{l}\text { A system analogous to } \\
\text { use of frozen } \\
\text { forecasts; } \\
\text { target-setting }\end{array}$ & $\begin{array}{l}\text { The word 'budget' } \\
\text { being literally } \\
\text { emphasised }\end{array}$ \\
\hline $\begin{array}{l}\text { Budgetary control } \\
\text { system in place }\end{array}$ & $\begin{array}{l}\text { RF; frozen forecasts; } \\
\text { target-setting }\end{array}$ & $\begin{array}{l}\text { RF; frozen forecasts; } \\
\text { target-setting, } \\
\text { budgeting of fixed } \\
\text { costs }\end{array}$ & $\begin{array}{l}\text { RF; frozen forecasts; } \\
\text { annual budgeting; } \\
\text { variance-analysis; } \\
\text { benchmarking }\end{array}$ \\
\hline $\begin{array}{l}\text { Independence of the } \\
\text { main processes }\end{array}$ & $\begin{array}{l}\text { Separate processes of } \\
\text { RF and target-setting }\end{array}$ & $\begin{array}{l}\text { Separate processes for } \\
\text { RF and } \\
\text { target-setting, } \\
\text { without the same } \\
\text { detail of information }\end{array}$ & $\begin{array}{l}\text { The same process, } \\
\text { actors, and detail of } \\
\text { information between } \\
\text { RF and the budget }\end{array}$ \\
\hline $\begin{array}{l}\text { Function emphasised } \\
\text { Use }\end{array}$ & Planning & Planning & Evaluation \\
\hline $\begin{array}{l}\text { Temporal orientation } \\
\text { of the planning }\end{array}$ & $\begin{array}{l}\text { Pre-period planning } \\
\text { stage: focus on RF } \\
\text { preparation }\end{array}$ & $\begin{array}{l}\text { Pre-period planning } \\
\text { stage: focus on RF } \\
\text { preparation }\end{array}$ & $\begin{array}{l}\text { Post-period planning } \\
\text { stage: variance } \\
\text { analysis important }\end{array}$ \\
\hline $\begin{array}{l}\text { Information about } \\
\text { factors in forecasting }\end{array}$ & $\begin{array}{l}\text { Systematic delivery of } \\
\text { information on the } \\
\text { variables for RF }\end{array}$ & $\begin{array}{l}\text { Systematic delivery of } \\
\text { information on the } \\
\text { variables for RF by } \\
\text { expert organisations }\end{array}$ & $\begin{array}{l}\text { Information about RF } \\
\text { variables that is } \\
\text { available on request }\end{array}$ \\
\hline $\begin{array}{l}\text { Effects of diagnostic or } \\
\text { interactive use }\end{array}$ & $\begin{array}{l}\text { Discussions and } \\
\text { challenging of } \\
\text { information, in } \\
\text { support of realistic } \\
\text { RF }\end{array}$ & $\begin{array}{l}\text { Discussions and } \\
\text { challenging of } \\
\text { information, in } \\
\text { support of realistic } \\
\text { RF }\end{array}$ & $\begin{array}{l}\text { Reporting of } \\
\text { deviations promotes } \\
\text { understanding about } \\
\text { uncontrollable } \\
\text { factors }\end{array}$ \\
\hline $\begin{array}{l}\text { Accuracy of } \\
\text { information }\end{array}$ & Planning accuracy & Planning accuracy & Budget accuracy \\
\hline $\begin{array}{l}\text { Planning of remedial } \\
\text { actions in the MCS }\end{array}$ & $\begin{array}{l}\text { Work based on } \\
\text { discussions: an } \\
\text { informal system of } \\
\text { variance analysis }\end{array}$ & $\begin{array}{l}\text { Work based on } \\
\text { discussion of } \\
\text { information before } \\
\text { calculation of } \\
\text { deviations }\end{array}$ & $\begin{array}{l}\text { Work based on } \\
\text { variance-analysis } \\
\text { meetings and ad hoc } \\
\text { top-management } \\
\text { meetings }\end{array}$ \\
\hline
\end{tabular}

$R F$ rolling forecasting

\section{References}

Abernethy, M. A., \& Brownell, P. (1999). The role of budgets in organisations facing strategic change: An exploratory study. Accounting, Organizations and Society, 24(3), 189-204.

Ahrens, T. (1997). Talking accounting: An ethnography of management knowledge in British and German Brewers. Accounting, Organizations and Society, 22(7), 617-637. 
Alvesson, M., \& Kärreman, D. (2004). Interfaces of control: Technocratic and socio-ideological control in a global management consultancy firm. Accounting, Organizations and Society, 29, 423-444.

Arwidi, O., \& Samuelson, L. A. (1993). The development of budgetary control in Sweden-A research note. Management Accounting Research, 4(2), 93-107.

Becker, S. D. (2014). When organisations deinstitutionalise control practices: A multiple-case study of budget abandonment. European Accounting Review, 23(4), 593-623.

Becker, S. D., Mahlendorf, M. D., Schäffer, U., \& Thaten, M. (2016). Budgeting in times of economic crisis. Contemporary Accounting Research, 33(4), 1489-1517.

Becker, S. D., \& Messner, M. (2013). Management control as temporal structuring. In K. Kaarbøe, P. N. Gooderham, \& H. Nørreklit (Eds.), Managing in dynamic business environments (pp. 141-162). Cheltenham: Edward Elgar.

Bisbe, J., Batista-Foguet, J.-M., \& Chenhall, R. H. (2007). Defining management accounting constructs: A methodological note on the risks of conceptual misspecification. Accounting, Organizations and Society, 32(7), 789-820.

Bisbe, J., \& Malagueño, R. (2009). The choice of interactive control systems under different innovation management modes. European Accounting Review, 18(2), 371-405.

Bøgsnes, B. (2009). Implementing beyond budgeting: Unlocking the performance potential. New York: Wiley.

Bourmistrov, A., \& Kaarbøe, K. (2013). From comfort to stretch zones: A field study of two multinational companies applying 'beyond budgeting' ideas. Management Accounting Research, 24(3), 196-211.

Bunce, P., Fraser, R., \& Woodcock, L. (1995). Advanced budgeting: A journey to advanced management systems. Management Accounting Research, 6(3), 253-265.

Burkert, M., Fischer, F. M., Hoos, F., \& Schuhmacher, K. (2017). The relationship between lack of controllability and proactive work behaviour: An empirical analysis of competing theoretical explanations. Accounting and Business Research, 47(2), 144-171.

Chapman, C. S. (1998). Accountants in organisational networks. Accounting, Organizations and Society, 23(8), 737-766.

Chenhall, R. H., \& Morris, D. (1995). Organic decision and communication processes and management accounting systems in entrepreneurial and conservative business organizations. Omega, 23(5), $485-497$.

Cosper, A. (2012). Keep on rolling. Entrepreneur, 40(2), 10.

Covaleski, M. A., Evans, J. H., Luft, J. L., \& Shields, M. D. (2003). Budgeting research: Three theoretical perspectives and criteria for selective integration. Journal of Management Accounting Research, 15(1), $3-49$.

Crant, J. M. (2000). Proactive behaviour in organizations. Journal of Management, 26(3), 435-462.

Eisenhardt, K. M. (1989). Building theories from case study research. The Academy of Management Review, 14(4), 532-550.

Ekholm, B., \& Wallin, J. (2000). Is the annual budget really dead? European Accounting Review, 9(4), 519-539.

Emmanuel, C., Otley, D., \& Merchant, K. (1990). Accounting for management control (2nd ed.). London: Chapman \& Hall.

Emsley, D. (2001). Redesigning variance analysis for problem solving. Management Accounting Research, 12(1), 21-40.

Ezzamel, M., \& Robson, K. (1995). Accounting in time: Time-reckoning and accounting practice. Critical Perspectives on Accounting, 6(2), 149-170.

Ferreira, A., \& Otley, D. (2009). The design and use of management control systems: An extended framework for analysis. Management Accounting Research, 20, 263-282.

Fisher, J. G., Frederickson, J. R., \& Peffer, S. A. (2000). Budgeting: An experimental investigation of the effects of negotiation. The Accounting Review, 75(1), 93-114.

Flamholtz, E. G. (1983). Accounting, budgeting and control systems in their organizational context: Theoretical and empirical perspectives. Accounting, Organizations and Society, 8(2/3), 153-169.

Frow, N., Marginson, D., \& Ogden, S. (2010). 'Continuous' budgeting: Reconciling budget flexibility with budgetary control. Accounting, Organizations and Society, 35(4), 444-461.

Goretzki, L. (2013). Management accounting and the construction of the legitimate manager. Journal of Management Control, 23, 319-344.

Goretzki, L., \& Messner, M. (2016). Coordination under uncertainty: A sensemaking perspective on crossfunctional planning meetings. Qualitative Research in Accounting \& Management, 13(1), 92-126. 
Grabner, I., \& Moers, F. (2013). Management control as a system or package? Conceptual and empirical issues. Accounting, Organizations and Society, 38(6-7), 407-419.

Haas, M. D., \& Kleingeld, A. (1999). Multilevel design of performance measurement systems: Enhancing strategic dialogue throughout the organization. Management Accounting Research, 10(3), 233-261.

Haka, S., \& Krishnan, R. (2005). Budget type and performance-The moderating effect of uncertainty. Australian Accounting Review, 15(1), 3-13.

Hansen, S. C. (2011). A theoretical analysis of the impact of adopting rolling budgets, activity-based budgeting and Beyond Budgeting. European Accounting Review, 20(2), 289-319.

Hansen, S. C., Otley, D. T., \& Van der Stede, W. A. (2003). Practice developments in budgeting: An overview and research perspective. Journal of Management Accounting Research, 15(1), 95-116.

Hansen, S. C., \& Van der Stede, W. A. (2004). Multiple facets of budgeting: An exploratory analysis. Management Accounting Research, 15(4), 415-439.

Henri, J.-F. (2006). Management control systems and strategy: A resource-based perspective. Accounting, Organizations and Society, 31(6), 529-558.

Henttu-Aho, T. (2016). Enabling characteristics of new budgeting practice and the role of controller. Qualitative Research in Accounting \& Management, 3(1), 31-56.

Henttu-Aho, T., \& Järvinen, J. (2013). A field study of the emerging practice of Beyond Budgeting in industrial companies: An institutional perspective. European Accounting Review, 22(4), 765-785.

Janke, R., Mahlendorf, M. D., \& Weber, J. (2014). An exploratory study of the reciprocal relationship between interactive use of management control systems and perception of negative external crisis effects. Management Accounting Research, 25(4), 251-270.

Järvenpää, M. (2007). Making business partners: A case study on how management accounting culture was changed. European Accounting Review, 16(1), 99-142.

Lillis, A., \& Mundy, J. (2005). Cross-sectional field studies in management accounting research-Closing the gaps between surveys and case studies. Journal of Management Accounting Research, 17(1), $119-141$.

Malmi, T., \& Brown, D. A. (2008). Management control systems as a package-Opportunities, challenges and research directions. Management Accounting Research, 19(4), 287-300.

Merchant, K., \& Van der Stede, W. A. (2007). Management control systems (4th ed.). Harlow: Prentice Hall, Pearson Education.

Mundy, J. (2010). Creating dynamic tensions through a balanced use of management control systems. Accounting, Organizations and Society, 35(5), 499-523.

Neely, A., Bourne, M., \& Adams, C. (2003). Better budgeting or beyond budgeting? Measuring Business Excellence, 7(3), 22-28.

Neuman, W. L. (2007). Basics of social research: Qualitative and quantitative approaches. Boston, MA: Allyn \& Bacon.

Østergren, K. (2009). Management control practices and clinician managers: The case of the Norwegian health sector. Financial Accountability \& Management, 25(2), 167-195.

Østergren, K., \& Stensaker, I. (2011). Management control without budgets: A field study of 'Beyond Budgeting' in practice. European Accounting Review, 20(1), 149-181.

Otley, D. T. (1978). Budget use and managerial performance. Journal of Accounting Research, 16(1), $122-149$.

Otley, D. T. (1987). Accounting control and organisational behaviour. London: CIMA.

Otley, D. T. (2001). Extending the boundaries of management accounting research: Developing systems for performance management. British Accounting Review, 33(3), 243-261.

Otley, D. T. (2006). Trends in budgetary control and responsibility accounting. In A. Bhimani (Ed.), Contemporary issues in management accounting. US: Oxford University Press.

Palermo, T. (2018). Accounts of the future: A multiple-case study of scenarios in planning and management control processes. Qualitative Research in Accounting \& Management, 15(1), 2-23.

Samuelson, L. A. (1986). Discrepancies between the roles of budgeting. Accounting, Organizations and Society, 11(1), 35-45.

Scapens, R. W. (2004). Doing case study research. In C. Humphrey \& B. Lee (Eds.), The real life guide to accounting research: A behind-the-scenes view of using qualitative research methods. UK: Elsevier.

Simons, R. (1991). Strategic orientation and top management attention to control systems. Strategic Management Journal, 12(1), 49-62.

Simons, R. (1995). Levers of control: How managers use innovative control systems to drive strategic renewal. USA: Harvard Business School Press. 
Sivabalan, P., Booth, P., Malmi, T., \& Brown, D. A. (2009). An exploratory study of operational reasons to budget. Accounting and Finance, 49(4), 849-871.

Sponem, S., \& Lambert, C. (2016). Exploring differences in budget characteristics, roles and satisfaction: A configurational approach. Management Accounting Research, 30, 47-61.

Tessier, S., \& Otley, D. (2012). A conceptual development of Simons' Levers of Control framework. Management Accounting Research, 23(3), 171-185.

Umapathy, S. (1987). Current budgeting practices in U.S. industry: The state of the art. New York: Quorum.

Van der Stede, W. A. (2000). The relationship between two consequences of budgetary controls: Budgetary slack creation and managerial short-term orientation. Accounting, Organizations and Society, 25(6), $609-622$.

Widener, S. K. (2007). An empirical analysis of the levers of control framework. Accounting, Organizations and Society, 32(7-8), 757-788.

Zeller, T. L., \& Metzger, L. M. (2013). Good bye traditional budgeting, hello rolling forecast: Has the time come? American Journal of Business Education, 6(3), 299-310.

Publisher's Note Springer Nature remains neutral with regard to jurisdictional claims in published maps and institutional affiliations. 